\title{
Systematic Errors in an Isoperibol Solution Calorimeter Measured with Standard Reference Reactions
}

\author{
Marthada V. Kilday* \\ National Bureau of Standards, Washington, D.C. 20234
}

July 23, 1980

\begin{abstract}
Systematic errors in an isoperibol calorimeter of a widely-used design, amounting to about 0.5 percent of the endothermic enthalpy of solution of SRM $1655(\mathrm{KCl})$ in $\mathrm{H}_{2} \mathrm{O}$, were found to be the result of errors in heat leak corrections due to inadequate stirring and commonly used calorimetric procedures.

Other systematic errors were found in measurements of the enthalpy of solution of the exothermic reaction of tris(hydroxymethyl)aminomethane in aqueous $\mathrm{HCl}$ solution.

Recommended procedures are summarized.

Key words: Calorimetry; enthalpy of solution; $\mathrm{KCl}$; solution calorimetry; standard reference materials; thermochemistry; tris(hydroxymethyl)aminomethane.
\end{abstract}

\section{Introduction}

Since the beginnings of calorimetry it has been recognized that compromises must be made with ideal conditions in order to design calorimeters for practical applications. It is always hoped that these compromises do not effect the accuracy of the measurements. Design criteria and possible sources of systematic errors in calorimeters have recently been discussed a priori in a series of papers by West, Churney, and Armstrong [1-4]. ${ }^{1}$ They also suggest experimental tests to determine whether some systematic errors are likely to occur during calorimetric measurements. Recent work [5] indicated disagreement in results obtained by three calorimeters believed to be capable of measurements of highest accuracy and experimental imprecision of 0.1 percent or less. Two of these were isoperibol calorimeters of the same design used by different scientists at different locations; the values measured for the

*Center for Thermodynamics and Molecular Science, National Measurement Laboratory.

${ }^{1}$ Figures in brackets indicate literature references at the end of this paper.

${ }^{2}$ The sample certified for the enthalpy of solution is designated SRM 1655. It is taken from the same lot as SRM 999, the primary analytical standard, and is available through the Office of Standard Reference Materials at the National Bureau of Standards (U.S.), Washington, D.C. 20234.

${ }^{2 a}$ Available through the Office of Standard Reference Materials at the National Bureau of Standards (U.S.), Washington, D.C. 20234. enthalpy of solution of $\mathrm{KBr}$ (from the same sample) differed by nearly 0.4 percent. The value obtained with the same sample of $\mathrm{KBr}$ using our adiabatic calorimeter differed by an additional 0.4 percent. It was apparent that an investigation of the sources of these errors was needed and this was the motivation in this work. It can be regarded as an incomplete work because more experimental work is needed before the specific reasons for some of the results can be given.

The standard reference reactions used in this work are (1) the solution of NBS Standard Reference Material (SRM) $1655^{2}, \mathrm{KCl}$, in $\mathrm{H}_{2} \mathrm{O}$ [6], and (2) the solution of SRM $724 \mathrm{a}^{2 \mathrm{a}}$, tris(hydroxymethyl)aminomethane (TRIS), in 0.1 $\mathrm{mol} \cdot \mathrm{dm}^{-3} \mathrm{HCl}$ solution [7]. The first reaction is endothermic and the second is exothermic.

The enthalpy of solution measurements were made in a commercially-available isoperibol calorimeter which had been previously modified [8] to make possible addition of measured amounts of electrical energy during the experiments. Results were obtained in this system using various calorimetric procedures in common use at high and low stirring rates. These results are compared with those obtained in a platinum-lined silver, vacuum-jacketed, adiabatic solution calorimeter [6,7,9] for which it has been demonstrated [9] that negligible corrections for heat transfer with the environment are required. 
The magnitudes of the errors found in this work may be different in other calorimeters, but the effects should be applicable to all isoperibol and some adiabatic calorimeters. Therefore, if the recommended procedures are followed, the sources of error identified here should be minimized; this can be confirmed by measurements of a standard reference reaction $[6,7,9,10]$.

\section{Materials, Apparatus, and Procedures}

The sample, SRM $1655(\mathrm{KCl})$, is described in detail in the next paper of this issue of the Journal of Research [6]. The portion, $C$, used here was not sieved but was dried by heating at $800 \mathrm{~K}$ for a total of $47 \mathrm{~h}$. The sample, SRM 724a (TRIS), had been stored at 50 percent relative humidity. The distilled $\mathrm{H}_{2} \mathrm{O}$ and the $\mathrm{HCl}$ solutions used as the calorimetric solutions were in equilibrium with the atmosphere, and no attempt was made to exclude $\mathrm{CO}_{2}$ in the air.

The calorimetric samples were contained in glass ampoules for powder (1.9 $\mathrm{cm}^{3}$ in volume) purchased from the LKB Company. ${ }^{3}$ Before filling with the samples, the ampoules were washed in $0.5 \mathrm{~mol} \cdot \mathrm{dm}^{-3} \mathrm{HCl}$ solution, thoroughly rinsed with distilled $\mathrm{H}_{2} \mathrm{O}$, dried overnight at about $400 \mathrm{~K}$, and stored in a desiccator until used. The sample was introduced (in the laboratory atmosphere) into a weighed ampoule through a glass funnel. Then it was weighed, and the temperature, relative humidity, and barometric pressure were recorded. The silicone rubber stopper was inserted and then coated with a beeswax. These calorimetric samples were prepared in groups of 7 to 16 so that the relative humidity $(\mathrm{RH})$ and other atmospheric conditions were similar for the samples in a given group. The first group of $11 \mathrm{KCl}$ samples $(\mathrm{RH}=\sim 55 \%)$ were used in the experiments reported in section 3.1 ; the second group of 16 samples $(\mathrm{RH}=\sim 65 \%)$ were used for the remainder of the $\mathrm{KCl}$ experiments; and the group of 7 TRIS samples $(\mathrm{RH}=\sim 55 \%)$ were used in the work described in section 4 .

The isoperibol solution calorimeter used in all of these measurements was one which was comunercially available but had been modified. The modifications made to this system are described in detail by Brunetti, et al. [8]. The

\footnotetext{
${ }^{3}$ Certain commercial materials are identified in this paper in order to specify the experimental procedures. Such identification does not imply recommendation or endorsement by the National Bureau of Standards.

${ }^{4} \mathrm{rpm}$ is revolutions per minute.
}

unmodified system had a maximum stirring rate of 500 $\mathrm{rpm}^{4}$ at $50 \mathrm{~Hz}$ or $600 \mathrm{rpm}$ at $60 \mathrm{~Hz}(700 \mathrm{rpm}$ was available in later models), and an approximately cylindrical glass reaction vessel. The cable drive for the stirrer-ampoule holder was replaced by an o-ring belt and pulley driven by a synchronous motor which provided a maximum stirring speed of $900 \mathrm{rpm}$ (measured by a stroboscope and a tachometer). The stirring was slightly improved by twisting the straight prongs of the ampoule holder about $45^{\circ}$ at the center to provide more turbulence in the solution. The approximately cylindrical glass reaction vessel with vertical re-entry wells was replaced by a nearly spherical vessel with re-entry wells slanted toward the bottom of the vessel. Another important modification was the addition of auxiliary equipment for the precise measurement of electrical energy (EE) introduced into the calorimeter. A quartz-oscillator thermometer was used instead of the usual thermistor for temperature measurements. In this work, the same quartz-oscillator probes were used in the reaction vessel and in the constant temperature jacket as in Brunetti's work but with separate power supplies for the oscillators and a counter for direct frequency counting using the $100 \mathrm{kHz}$ standard frequency supplied at NBS. The results of recalibration of the quartz oscillators by comparison with a calibrated platinum resistance thermometer over the range of $295 \mathrm{~K}$ to $306 \mathrm{~K}$ showed an uncertainty in the absolute temperature of $0.1 \mathrm{~K}$; the absolute value is of relatively little importance in this work, but the temperature changes are of major interest because they are used directly to measure energy changes.

In all of the experiments described here, timetemperature readings at 100 -s intervals were recorded on punched paper tape and printed on a teletype. Rating periods consisted of 7 to 9 of these readings. Main periods for calibrations or reactions were 15 to $30 \mathrm{~min}$; three different times were chosen for the end of each main period and a corrected $\Delta T$ (the temperature change of the calorimeter corrected for heat leak) was calculated at each time as a check on the achievement of the single exponential curve desired for rating periods. Each experiment included electrical calibrations of the initial and final system, and a measurement on the reaction with or without the addition of electrical energy. The corrected $\Delta T$ was calculated by Nuttall's method of calculation described previously [8]. The system for measuring electrical energy was also described [8] and the calculations were similar to those given in [7].

The 1975 Table of Atomic Weights [11] was used to obtain the following relative molar masses used in this work: $\mathrm{KCl}, 74.5513$; TRIS, 121.1358; and $\mathrm{H}_{2} \mathrm{O}, 18.0152$. For unit conversions, 4.184 joules $=1$ thermochemical calorie. 


\section{Endothermic Reactions of SRM 1655 $(\mathrm{KCl})$ in $\mathrm{H}_{2} \mathrm{O}$}

In the following subsections $(3.1,3.2$, and 3.3), experimental evidence is presented which isolates and indicates errors in corrections for heat transfer between the reaction vessel and the environment (heat leak) due to inadequate stirring and objectionable calorimetric procedures. It must be emphasized that the magnitudes of the errors revealed here apply only to the reaction of $\mathrm{KCl}$ in $\mathrm{H}_{2} \mathrm{O}$ under these conditions in this calorimeter, although the observed effects may apply to most isoperibol and some adiabatic calorimeters. Calorimeters of different designs may have errors of different magnitudes, and the magnitude of errors may be different for different reactions in a given calorimeter. Thus, it is not enough to obtain the correct value for a standard reference reaction because compensating errors may exist which would be different for another reaction. It therefore becomes necessary to show that the sources of error found in this work are not present in each design of calorimeter for each reaction, if the results are to be considered accurate to better than several percent.

The molality range for all measurements described here is $m=0.085$ to $0.102 \mathrm{~mol} \cdot \mathrm{kg}^{-1}$. The dilution corrections, $(0.33 \pm 0.01) \mathrm{kJ} \cdot \mathrm{mol}^{-1}$, are the same as those in the work with the adiabatic calorimeter [6] and for the enthalpy of solution value recommended by the Physical Chemistry Division of IUPAC [12].

The following definitions apply to all tables in this paper:

The Experiment Number is a serial number for experiments with this calorimeter and indicates the chronological order of the experiments.

The mass of calorimetric samples and solutions is obtained by correcting the weighings to vacuum using the following factors: 1.000455 for $\mathrm{KCl}, 1.000732$ for TRIS, and 1.00104 for $\mathrm{H}_{2} \mathrm{O}$ and for $0.1 \mathrm{~mol} \cdot \mathrm{dm}^{-3} \mathrm{HCl}$.

The Electrical Energy Equivalent of the initial and final systems, $\epsilon_{i}$ and $\epsilon_{f}$, is $\operatorname{EIt}(\Delta T)^{-1}$ where $\mathrm{E}$ is the potential drop across the calorimeter heater, $I$ is the current through the heater, $t$ is the time of heating, and $\Delta T$ is the corrected temperature change.

$\Delta T_{\text {obs }}$ is the observed temperature change during the reaction period or the difference between the final and initial temperatures of the reaction period, $T_{f}-T_{i}$.

The "correction" is the temperature change caused by heat leak and constant energy sources such as stirring (see [8]). The corrected temperature rise is $\Delta T_{\text {corr }}=$ $\Delta T_{\text {obs- }}$-correction.

$E E$ is the work done on the calorimeter system or the electrical energy, EIt (defined above), introduced during endothermic reactions to prevent a decrease in the calorimeter temperature.

$q_{\text {vap }}$ is the correction for the heat of vaporization of water into the air space contained in the sample ampoule. $-q_{\text {vap }}=$ $\Delta H_{\text {vap }}[V-(s / d)](1-\mathrm{RH})$ where $\Delta H_{\text {vap }}$ is the enthalpy of vaporization of water per unit volume at the mean temperature of the reaction $\left(0.0563 \mathrm{~J} \cdot \mathrm{cm}^{-3}\right.$ at $\left.298 \mathrm{~K}\right), V$ is the internal volume of the sample holder $\left(1.0 \mathrm{~cm}^{3}\right), \mathrm{s}$ is the mass of sample, $d$ is the density of the sample $\left(1.98 \mathrm{~g} \cdot \mathrm{cm}^{-3}\right.$ for $\mathrm{KCl}$ and $1.35 \mathrm{~g} \cdot \mathrm{cm}^{-3}$ for TRIS), and $\mathrm{RH}$ is the relative humidity of the atmosphere in which the sample was transferred to the ampoule.

The energy absorbed during the endothermic reaction, $-Q$, or evolved during the exothermic reaction, $Q$, is obtained from the following equation:

$$
Q=\Delta T_{\text {corr }}\left(\frac{\epsilon_{i}+\epsilon_{f}}{2}\right)-E E-q_{\text {vap }} \text {. }
$$

$E E=0$ for exothermic reactions and those endothermic reactions where the calorimeter temperature was allowed to decrease during the reaction.

The mean temperature of reaction, $T_{r}$, or $\left(T_{i}+T_{f}\right) / 2$ is taken as the reaction temperature.

The specific enthalpy of reaction at the reaction temperature, $\Delta H\left(T_{r}\right)$, is $-Q \cdot \mathrm{s}^{-1}$ in $\mathrm{J} \cdot \mathrm{g}^{-1}$; multiply this value by the molar mass $\times 10^{-3}$ to obtain the molar enthalpy of reaction in $\mathrm{kJ} \cdot \mathrm{mol}^{-1}$.

The correction to $T=298.15 \mathrm{~K}$, $\operatorname{Corr}_{S T}$, uses $\Delta C_{p}=$ $-0.1548 \mathrm{~kJ} \cdot \mathrm{mol}^{-1} \cdot \mathrm{K}^{-1}$ for $\mathrm{KCl}[6]$ and $0.1738 \mathrm{~kJ} \cdot \mathrm{mol}^{-1} \cdot \mathrm{K}^{-1}$ for TRIS [7]. Then

$$
\Delta H(298.15 \mathrm{~K})=\Delta H\left(T_{r}\right)-\Delta C_{p}\left(T_{r}-298.15 \mathrm{~K}\right) .
$$

The correction to infinite dilution, $\Phi_{L}$ for $\mathrm{KCl}$ was obtained from Parker's table XV A [13].

The standard enthalpy of solution, $\Delta H^{\circ}(\infty, 298.15 \mathrm{~K})$, is $\Delta H\left(T_{r}\right)-\operatorname{Corr}_{S T}-\Phi_{L}$. The correction to infinite dilution was not applied in the TRIS results since comparisons are made at the concentration, $5 \mathrm{~g}$ TRIS/L of $0.1 \mathrm{~mol} \cdot \mathrm{dm}^{-3} \mathrm{HCl}$.

$T_{A}$ and $T_{B}$ are the mean temperatures of the initial and final calibrations, respectively.

$T_{\epsilon}$ is the mean temperature of the two electrical calibrations, $\left(T_{A}+T_{B}\right) / 2$.

$T_{j}$ is the constant jacket temperature which is the mean of two readings taken before and after each experiment.

$T_{B f}, T_{A i}$, and $T_{A f}$ are the final temperature of the final calibration and the initial and final temperatures of the initial calibration, respectively. 
The Reaction Period is the elapsed time between initiating the reaction (or electrical heating) and the beginning of the final rating period.

$k$ is the heat leak modulus or cooling constant.

$U$ represents contributions to the temperature change from constant energy sources and is sometimes referred to as the stirring energy.

$T(\infty)$ is the convergence temperature or the temperature which the calorimeter would attain in an infinite time if the jacket temperature and the rate of stirring remained constant.

The energy for breaking the glass ampoules was measured in six experiments. The ampoules contained distilled $\mathrm{H}_{2} \mathrm{O}$ in the first three experiments, and air in the last three. The breaking energies were as follows: 1.56, $-0.05,-0.39 \mathrm{~J}[$ mean $=(0.37 \pm 0.60)]$; and $-0.46,1.21$, $-0.23 \mathrm{~J} \quad[$ mean $=0.17 \pm 0.52) \mathrm{J}]$. The last three measurements include $0.02 \mathrm{~J}$ as the correction for vaporization of $\mathrm{H}_{2} \mathrm{O}$ into the air in the ampoule. The uncertainties are the standard deviations of the means. Since these uncertainties are larger than the mean values, no corrections are made for the breaking energies in this work and the uncertainty is included in the experimental uncertainty. It should be noted that these uncertainties would probably have been smaller for a more experienced operator; these experiments were the author's first measurements with this calorimeter, and the manual operation of the bulb-breaking mechanism may have become more reproducible later. (It was observed that the uncertainty in the bulb-breaking was about 3 times the experimental random errors in the $\mathrm{KCl}$ experiments.) The large uncertainty may also be the result of erratic $k$ values when the temperature change is small; this will be discussed in section 3.2.1. In non-calorimetric experiments, it was also observed that when the bulb-breaking spring mechanism was compressed, the stirrer stopped until the spring was released. Thus, the error in the stirring energy depends on the time the spring remained compressed as well as the extent to which the stirring duplicated the conditions prior to breaking the ampoule.

In this work, no special effort has been made to achieve low experimental imprecision by precisely reproducing experimental conditions, although general procedures have been adhered to in order to obtain comparable results under varying conditions. This work shows that highly reproducible measurements can be inaccurate by several percent.

\subsection{Stirring}

The source of error for endothermic or exothermic reactions, which is easiest to identify and correct is that due to inadequate stirring, and yet too frequently the effectiveness of stirring during a reaction is not confirmed.

In preliminary non-calorimetric experiments for this work, a rack was built near the calorimeter jacket to support the reaction vessel assembly which includes the covers for the jacket and the well. This assembly was mounted so that the same motor and belt drove the stirrer as in the calorimetric experiments. The reaction vessel was assembled exactly as in a calorimetric experiment except that the well was not attached, and the glass reaction vessel could be observed. At $400 \mathrm{rpm}$, when the ampoule containing $\mathrm{KCl}$ was broken, the crystals dropped to the bottom, with solution occurring primarily at the surface of the crystals. A conically-shaped helix of more concentrated solution (with different refractive index) was observed between the mass of crystals at the bottom and the stirrer (about $2 \mathrm{~cm}$ above). After several minutes, the reaction was proceeding so slowly that the stirring rate was increased to $550 \mathrm{rpm}$, the next step available. The crystals remained at the bottom of the vessel although the liquid was swept more rapidly over the surface of the crystals. The vessel was then reassembled with another sample; this time the stirring was at $900 \mathrm{rpm}$, the next and highest stirring rate available with this pulley arrangement. When the ampoule was broken, most of the crystals were stirred up into the solution although a few of the larger crystals "danced" on the bottom for about one-half minute. The latter problem could have been eliminated by sieving the sample to remove the larger particles.

Large stirring energies are regarded as undesirable although the corrections can be made with reasonable accuracy. With temperature sensing instruments in current use, the "hot or cold spot" effects due to inadequate stirring cannot be adjusted in the heat leak corrections. Therefore, the adequacy of stirring should be verified for each reaction.

Some metal or silvered Dewar calorimeter vessels preclude the possibility of viewing a reaction in the vessel. In these cases, a replica or "dummy" vessel can be made of glass having the same size and shape as the reaction vessel for the purpose of observing reactions and stirring characteristics.

A possible alternative to visual confirmation that a reaction is adequately stirred is a series of calorimetric measurements at various stirring speeds. If the leveling-off of a changing enthalpy value can be observed, it may be an indication that adequate stirring has been achieved. However, continuously changing or constant enthalpy values with increasing stirring speeds may indicate that adequate stirring is never accomplished. At $900 \mathrm{rpm}$, the solution of the $\mathrm{KCl}$ appeared to be complete in about 2 min; at the slower speeds 5 to 10 min were required. 
In table 1 are the results of two sets of measurements of the enthalpy of solution of SRM 1655 in $\mathrm{H}_{2} \mathrm{O}$, set 1 at 400 rpm (observed to be an inadequate stirring rate) and set 2 at $900 \mathrm{rpm}$ (observed to be adequate). Expt. 10 in the second set was omitted from the mean because the slopes of the rating periods preceding the reaction were significantly smaller than in the other experiments, which was evidence of prereaction.

In all experiments in table 1 , electrical energy was added during the endothermic reaction to prevent a decrease in the calorimeter temperature. The rapid absorption of energy by the reaction necessitated heating at about $1.2 \mathrm{~W}$ in the $82.3-\Omega$ heater $(9.75 \mathrm{~V}$ and $0.118 \mathrm{~A})$. Electrical heating was started about $100 \mathrm{~s}$ before breaking the ampoule containing $\mathrm{KCl}$; thus, the calorimeter temperature was rising when the reaction was initiated. The greatest decrease in the calorimeter temperature recorded for the 100 -s interval was $6 \mathrm{mK}$ at $400 \mathrm{rpm}$ and $39 \mathrm{mK}$ at 900 rpm. Without addition of electrical energy it was nearly $300 \mathrm{mK}$.

The mean value for $\Delta H^{\circ}(\infty, 298.15 \mathrm{~K})$ in table 1 , $17.224 \mathrm{~kJ} \cdot \mathrm{mol}^{-1}$, at $900 \mathrm{rpm}$ is $0.078 \mathrm{~kJ} \cdot \mathrm{mol}^{-1}(\sim 0.5 \%)$ greater than that at $400 \mathrm{rpm}$ although the standard deviations of the mean $(\mathrm{Sdm})$ are both less than 0.02 $\mathrm{kJ} \cdot \mathrm{mol}^{-1}(\sim 0.1 \%$, or $\sim 0.3 \%$ at the $95 \%$ confidence level). This is the direction of the error to be expected when a cold spot absorbs energy from the environment, resulting in a smaller temperature change apparently due to the reaction.

As expected the variations in some of the parameters appear to have no significant effect on the results; i.e., variations in the reaction period from 1300 to $1800 \mathrm{~s}$, final temperature $\left(T_{B j}\right)$ from 0.1 to $0.5 \mathrm{~K}$ below the jacket

Table 1. Measurements of the enthalpy of solution of SRM 1655 (KC1) in $\mathrm{H}_{2} 0$ using a stirring rate observed to be inadequate (400 rpm) and one observed to be adequate $(900 \mathrm{rpm})$. Electrical energy was added during the reactions (Method $A$ ).

(a) Calculation of enthalpy of solution:

\begin{tabular}{|c|c|c|c|c|c|c|c|c|c|c|c|c|c|c|}
\hline \multirow{2}{*}{$\begin{array}{r}\text { Expt. } \\
\text { No. }\end{array}$} & \multicolumn{2}{|r|}{ Mass } & Elect. Energy Equiv. & \multirow{2}{*}{$\Delta \mathrm{T}_{\mathrm{obs}}$} & \multirow{2}{*}{ Correction } & \multirow[b]{2}{*}{$\mathrm{EE}$} & \multirow[b]{2}{*}{$-q_{\text {vap }}$} & \multirow[b]{2}{*}{$-Q$} & \multirow{2}{*}{\multicolumn{2}{|c|}{$\Delta \mathrm{H}\left(\mathrm{T}_{\mathrm{r}}\right)$}} & \multirow[b]{2}{*}{$\mathrm{T}_{\mathrm{r}}$} & \multirow[b]{2}{*}{${ }^{\text {Corr }}$ ST } & \multirow[b]{2}{*}{$\Phi_{L}$} & \multirow{2}{*}{$\frac{\Delta \mathrm{H}^{\circ}(\infty, 298.15 \mathrm{~K})}{\mathrm{kJ} / \mathrm{mo} 1}$} \\
\hline & $\mathrm{KC1}$ & $\mathrm{H}_{2} \mathrm{O}$ & \begin{tabular}{ll|l} 
Intitial Final \\
\end{tabular} & & & & & & & & & & & \\
\hline
\end{tabular}

(1) Stirring Rate: $400 \mathrm{rpm}$

\begin{tabular}{l|r|r|r|l}
11 & 0.80454 & 107.353 & 483.19 & 481.17 \\
15 & .80783 & 107.342 & 482.22 & 480.77 \\
16 & .79847 & 107.350 & 483.29 & 480.97 \\
18 & .78384 & 107.357 & 483.55 & 482.09 \\
19 & .75008 & 107.372 & 483.29 & 481.32
\end{tabular}

\begin{tabular}{|r|r}
0.32914 & 0.13882 \\
.19420 & .13398 \\
.39565 & .21316 \\
.31571 & .12382 \\
.31046 & .17070
\end{tabular}

$\left|\begin{array}{l}279.415 \\ 217.654 \\ 275.570 \\ 275.777 \\ 253.275\end{array}\right|$

0.015
.015
.015
.016
.016

\begin{tabular}{|l|l|l|l|}
187.631 & 233.216 & 17.386 & 298.6045 \\
188.643 & 233.519 & 17.409 & 298.3219 \\
187.571 & 234.913 & 17.513 & 298.3166 \\
183.113 & 233.610 & 17.416 & 298.5800 \\
175.852 & 234.444 & 17.478 & 298.2898
\end{tabular} \mid

\begin{tabular}{r|r|}
0.070 & 0.336 \\
.027 & .337 \\
.026 & .336 \\
.067 & .335 \\
.022 & .332
\end{tabular}

17.120

17.099

17.202

17.148

17.168

\begin{tabular}{|c|c|c|c|}
\hline 9 & 0.67699 & 107.353 & 483.20 \\
\hline 10 & .80211 & 107.358 & 487.28 \\
\hline & .79497 & 107.348 & 483.78 \\
\hline & .71114 & 107.373 & 484.01 \\
\hline & .79600 & 107.344 & 483.47 \\
\hline & .79693 & 107.364 & 484.44 \\
\hline
\end{tabular}

\begin{tabular}{|}
0.46423 \\
.39237 \\
.44786 \\
.46209 \\
.45050 \\
.42493
\end{tabular}

\begin{tabular}{l|l}
0.21571 & 279.024 \\
.24068 & 258.441 \\
.26727 & 274.186 \\
.23718 & 275.673 \\
.26024 & 279.344 \\
.23726 & 277.889
\end{tabular}

\begin{tabular}{|}
0.017 \\
.015 \\
.015 \\
.016 \\
.015 \\
.015
\end{tabular}

$\left|\begin{array}{l}159.127 \\ 184.597 \\ 187.012 \\ 166.983 \\ 187.570 \\ 187.228\end{array}\right|$

\begin{tabular}{|l|l|l|}
235.051 & 17.523 & 298.2098 \\
230.139 & 17.157 & 298.3873 \\
235.242 & 17.538 & 298.3654 \\
234.812 & 17.506 & 298.3595 \\
235.641 & 17.567 & 298.3831 \\
234.936 & 17.515 & 298.2969
\end{tabular}

\begin{tabular}{|l|r|}
0.009 & 0.326 \\
.037 & .336 \\
.033 & .336 \\
.032 & .329 \\
.036 & .336 \\
.023 & .336
\end{tabular}

17.206

$16.858^{\mathrm{b}}$

17.235

17.209

17.267

17.202

Mean $=17.224^{\mathrm{a}}$

$\mathrm{Sdm}=0.012$

(b) Other calorimetric parameters:

\begin{tabular}{|c|c|c|c|c|c|c|c|c|c|}
\hline $\begin{array}{l}\text { Expt. } \\
\text { No. }\end{array}$ & $\mathrm{T}_{\mathrm{A}}$ & $\mathrm{T}_{\mathrm{B}}$ & $\mathrm{T}_{\varepsilon}-\mathrm{T}_{\mathrm{r}}$ & $\mathrm{T}_{\mathrm{j}}$ & $\mathrm{T}_{\mathrm{Bf}}$ & $\begin{array}{l}\text { Reaction } \\
\text { Period }\end{array}$ & $\mathrm{k} \times 10^{-6}$ & $\mathrm{U} \times 10^{-6}$ & $\mathrm{~T}(\infty)$ \\
\hline & $\mathrm{K}$ & $\mathrm{K}$ & $\mathrm{R}$ & $\mathrm{K}$ & $\mathrm{K}$ & $\mathrm{s}$ & $s^{-1}$ & $\mathrm{~K} / \mathrm{s}$ & $\mathrm{K}$ \\
\hline \multicolumn{10}{|c|}{ (1) Stirring Rate: $400 \mathrm{rpm}$} \\
\hline 11 & 298.046 & 299.032 & -0.065 & 299.488 & 299.246 & 1500 & 118 & -1.1 & 299.479 \\
\hline 15 & 298.322 & 299.016 & +.347 & 299.482 & 299.210 & 1500 & 113 & 2.6 & 299.505 \\
\hline 16 & 297.619 & 298.823 & -.096 & 299.481 & 299.054 & 1700 & 119 & -2.0 & 299.464 \\
\hline 18 & 297.979 & 299.154 & -.013 & 299.481 & 299.380 & 1300 & 116 & 1.0 & 299.489 \\
\hline 19 & 297.658 & 298.764 & -.079 & 299.481 & 298.989 & 1300 & 120 & -3.2 & 299.455 \\
\hline
\end{tabular}

(2) Stirring Rate: $900 \mathrm{rpm}$

\begin{tabular}{r|l|l|l|l|l|l|l|l|l}
9 & 297.532 & 298.783 & -0.052 & 299.487 & 299.050 & 1300 & 122 & 22.6 & 299.672 \\
10 & 297.703 & 298.918 & -.077 & 299.488 & 299.186 & 1600 & 122 & 24.6 & 299.689 \\
12 & 297.609 & 298.928 & -.097 & 299.487 & 299.189 & 1800 & 120 & 24.3 & 299.690 \\
13 & 297.635 & 298.960 & -.062 & 299.487 & 299.226 & 1600 & 116 & 28.9 & 299.735 \\
14 & 297.613 & 298.921 & -.116 & 299.481 & 299.158 & 1800 & 118 & 25.7 & 299.699 \\
17 & 297.569 & 298.858 & -.084 & 299.481 & 299.136 & 1500 & 118 & 26.3 & 299.703
\end{tabular}

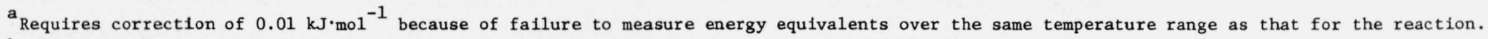

omitted from mean. 
temperature $\left(T_{j}\right)$, and difference between the mean temperature of the calibration and that of the reaction $\left(T_{\epsilon}-T_{r}\right)$ from -0.12 to $+0.35 \mathrm{~K}$. The values for $k$ are essentially the same for the two sets, and the spread of the $U$ values is similar in the two sets although it is to be expected that the magnitude is different at the different stirring rates.

The corrected value for $\Delta H^{\circ}(\infty, 298.15 \mathrm{~K})$ in set $2^{5}(900$ $\mathrm{rpm}), 17.234 \mathrm{~kJ} \cdot \mathrm{mol}^{-1}$, is in excellent agreement with that obtained from measurements with the same sample in the adiabatic calorimeter, $17.241 \mathrm{~kJ} \cdot \mathrm{mol}^{-1}$ [6] where heat leak corrections are negligible.

\subsection{Addition of Electrical Energy During Endothermic Reactions}

Most solution calorimeters used in research work are equipped with instrumentation for the direct measurement of electrical energy introduced during electrical calibrations (and endothermic reactions). However, this facility is not available in some calorimeters (including the original configuration of the one used here). Such systems generally require indirect methods for arriving at the amount of electrical energy introduced into the calorimeter during calibrations, and electrical energy is usually not added during endothermic reactions. These methods may be subject to uncertainties due to changes in resistances (assumed to be constant) with time and varying conditions. In the procedure where electrical energy is not added during the endothermic reaction, the vessel temperature decreases as energy is absorbed by the endothermic reaction; this procedure is questionable because of thermal lags in the systems which may be different for increasing vessel temperatures (as in electrical calibrations) and for decreasing vessel temperatures (as in endothermic reactions). The work in this section was designed to show whether significant errors can be detected in this procedure.

The experiments in section 3.1 were performed with the addition of precisely measured electrical energy during the endothermic reactions (Method A). The vessel temperature was constantly rising throughout the experiment, and the mean temperature of the initial and final calibration periods differed from that of the reaction period by about $0.1 \mathrm{~K}$ or less (one exception was $0.3 \mathrm{~K}$ ). The observed temperature

\footnotetext{
${ }^{5}$ The results in section 4 indicate a systematic error estimated to be 0.06 percent due to failure to measure the energy equivalents over the same temperature range as the reaction. This would increase the mean value by $0.01 \mathrm{~kJ} \cdot \mathrm{mol}^{-1}$ which would still be within the experimental uncertainty of the value obtained from measurements in the adiabatic calorimeter.
}

change in the reaction period was about the same as those of the calibration periods.

These experiments will be compared with those in table 2 in which electrical energy was not introduced during the reaction period (Method $B$ ); set 1 was at the inadequate stirring rate of $400 \mathrm{rpm}$, and set 2 at the adequate rate of $900 \mathrm{rpm}$. The vessel temperature increased about $0.6 \mathrm{~K}$ during calibration periods and decreased about $0.2 \mathrm{~K}$ (including the heating effects of the stirring energy) during the reaction periods; the corrected temperature changes were about equal $(0.4 \mathrm{~K})$ but in opposite directions. The differences between the mean temperature of the initial and final calibration periods and that of the reaction period were about $0.1 \mathrm{~K}$ or less.

Comparison of the mean values of $\Delta H^{\circ}(\infty, 298.15 \mathrm{~K})$ obtained by Methods A and B (tables 1 and 2) for set 1 at the inadequate stirring rate $(400 \mathrm{rpm})$ indicates a difference of $0.05 \mathrm{~kJ} \cdot \mathrm{mol}^{-1}(0.3 \%)$. The value for set 1 , Method B is nearly as large as that for Method $\mathrm{A}$ at the higher stirring rate $(900 \mathrm{rpm})$ which agrees with the value measured in the adiabatic calorimeter. This indicates partially compensating errors in set 1, Method B due to inadequate stirring and thermal lags resulting from an objectionable calorimetric procedure.

Comparison of Methods A and B at the higher stirring rate, $900 \mathrm{rpm}$, in the sets 2 is more difficult because of the erratic results obtained with Method B where the imprecision was about 5 times that in the other sets. From the order of the experiment numbers, it can be seen that the experiments in the erratic set 2 alternated with those in set 1 . Thus it is unlikely that a change in the system caused the erratic results. It is also unlikely that the erratic results were caused by the higher stirring rate since low imprecision was obtained in the set 2 experiments in table 1. Henceforth attention will be focused on the two sets of experiments at the higher stirring rate, $900 \mathrm{rpm}$, where the results are not complicated by the problems of inadequate stirring. The possible causes of the erratic results will be discussed in the following subsection.

\subsubsection{Analysis of Results Where Electrical Energy Was Not Added During the Endothermic Process}

The erratic enthalpy of solution values obtained in the experiments in set 2 of table 2 cannot be fully explained here because more experimental work is needed before the cause of some of the problems can be specifically identified. However, it will be shown that relatively large errors were introduced in Method B which were not present in Method A. The large spread of the enthalpy values was probably the result of several uncertainties and errors such as the loss of significance in the cooling constant, $k$, discontinuity 
Table 2. Measurements of the enthalpy of solution of SRM 1655 (KC1) in $\mathrm{H}_{2} \mathrm{O}$ without the addition of electrical energy during the reactions (Method $\mathrm{B}$ ) at two stirring rates.

(a) Calculation of enthalpy of solution:

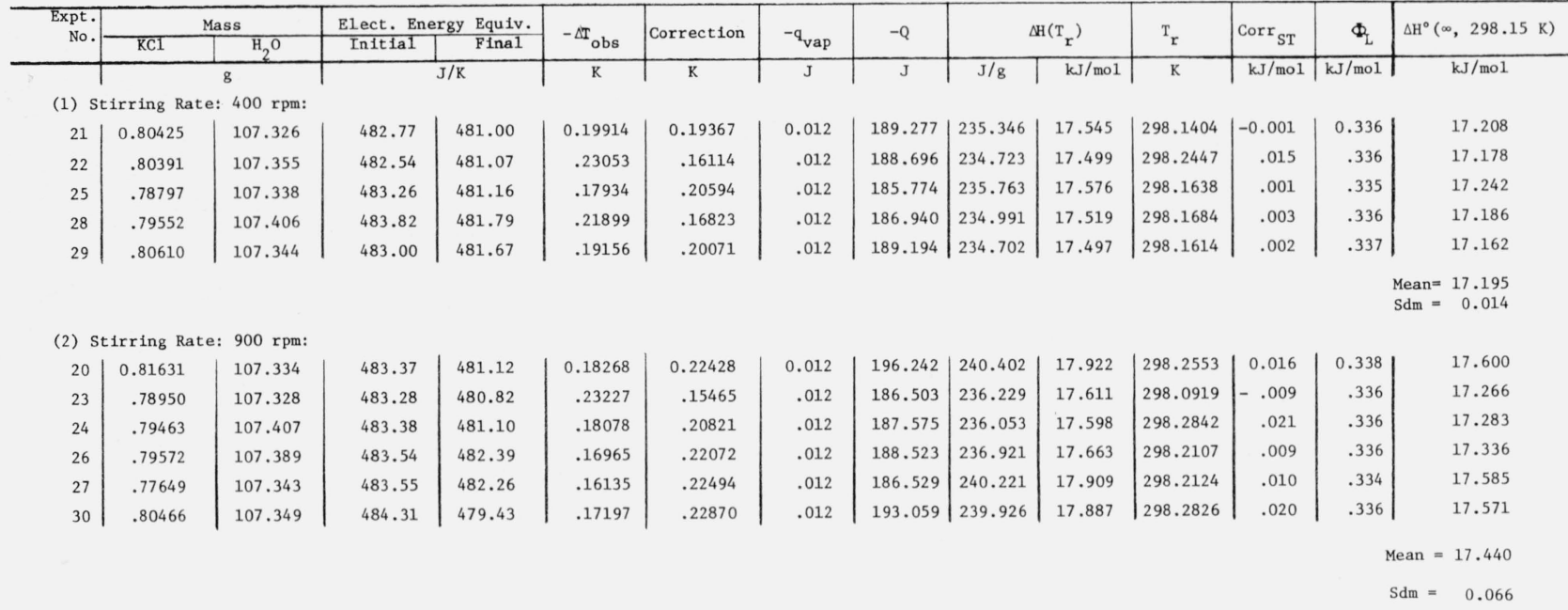

(b) Other calorimetric parameters:

\begin{tabular}{r|c|c|c|c|c|c|c|c|c}
\hline $\begin{array}{r}\text { Expt. } \\
\text { No. }\end{array}$ & $\mathrm{T}_{\mathrm{A}}$ & $\mathrm{T}_{\mathrm{B}}$ & $\mathrm{T}_{E}-\mathrm{T}_{\mathrm{r}}$ & $\mathrm{T}_{\mathrm{j}}$ & $\mathrm{T}_{\mathrm{Bf}}$ & $\begin{array}{c}\text { Reaction } \\
\text { Period }\end{array}$ & $\mathrm{k} \times 10^{-6}$ & $\mathrm{U} \times 10^{-6}$ & $\mathrm{~T}(\infty)$ \\
\hline & $\mathrm{K}$ & $\mathrm{K}$ & $\mathrm{K}$ & $\mathrm{K}$ & $\mathrm{K}$ & $\mathrm{s}$ & -1 & $\mathrm{~K} / \mathrm{s}$ & $\mathrm{K}$ \\
(1) Stirring Rate: $400 \mathrm{rpm}$ \\
21
\end{tabular}

in the stirring energy when the ampoule was broken, abnormal thermal lags, effects of condensation and evaporation of water, and possibly others.

In table $2 \mathrm{~b}$, the spread of the values for the cooling constant for set 2 , is about 3 times that for set 1 and for both sets in table 1 . The variations in $k$ are similar to those in the values for the enthalpy of solution. These large variations in the $k$ values are partly the result of the loss of 1 or 2 orders of significance because there is little difference between the slopes and between the mean temperatures of the rating periods preceding and following the solution of $\mathrm{KCl}$ when using Method B: Figure 1 shows that the differences in the slopes and in the mean temperatures of the rating periods before and after the solution of $\mathrm{KCl}$ in Expt. No. 9 (Method A, set 2) are large compared to those in Expt. No. 20 (Method B, set 2).

Figure 2 is a plot of the rating period slopes as a function of the difference between the jacket temperature and the mean temperature of the rating period, for Expt. No. 17 (Method A, set 2) and for Expt. No. 20 (Method B, set 2); the data for this plot are given in table 3 . The points from Expt. No. 17, where electrical energy was added during the reaction period, lie along a nearly straight line; this is to be expected if Newton's law of cooling is valid in the experiment. However, in Expt. No. 20, where electrical energy was not added during the reaction period, the points for the rating periods preceding the reaction were on a different line than that for the rating periods following the reaction; this would indicate a disturbance of the constant power sources or of the heat transfer coefficients during this reaction period.

Figure 3 is a plot of the $k$ values as a function of $\left(T_{\infty}-T\right)$ from the electrical calibrations and from the reaction periods for the set 2 experiments in tables 1 and 2 . This plot shows a disturbing temperature dependence of the $k$ values. It also shows that the final values for $\left(T_{\infty}-T\right)$ were 


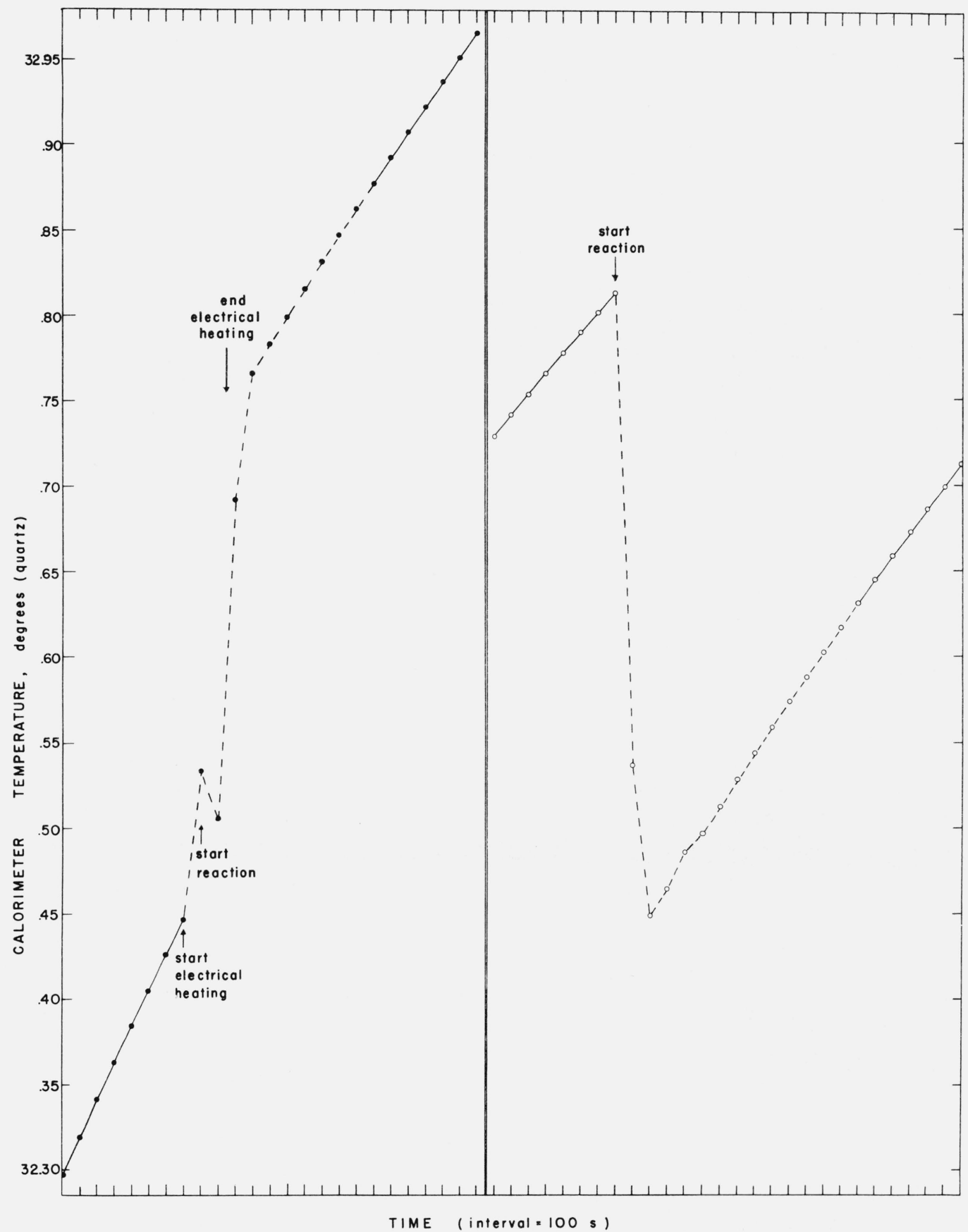

FIGURE 1. A plot of the calorimeter temperature us. time for the reaction periods of 2 experiments using adequate stirring, 900 $r p m$, in which the enthalpy of solution of $\mathrm{KCl}$ was measured using different procedures.

At left (filled circles), electrical energy was added during the reaction period to prevent a decreasein the vessel temperature during the endothermic solution of $\mathrm{KCl}$ (Expt. No. 9, table 1, Method A); at right (open circles), no electrical energy was added and the vessel temperature decreased (Expt. No. 20, table 2, Method B). Points in the rating periods are connected by continuous lines; those in the reaction periods, by broken lines. The calorimeter temperatures are the readings on the quartz-oscillator thermometer where 1 degree $\cong 1 \mathrm{~K}$ and 32.62 degrees (quartz) $=298.15 \mathrm{~K}$. 


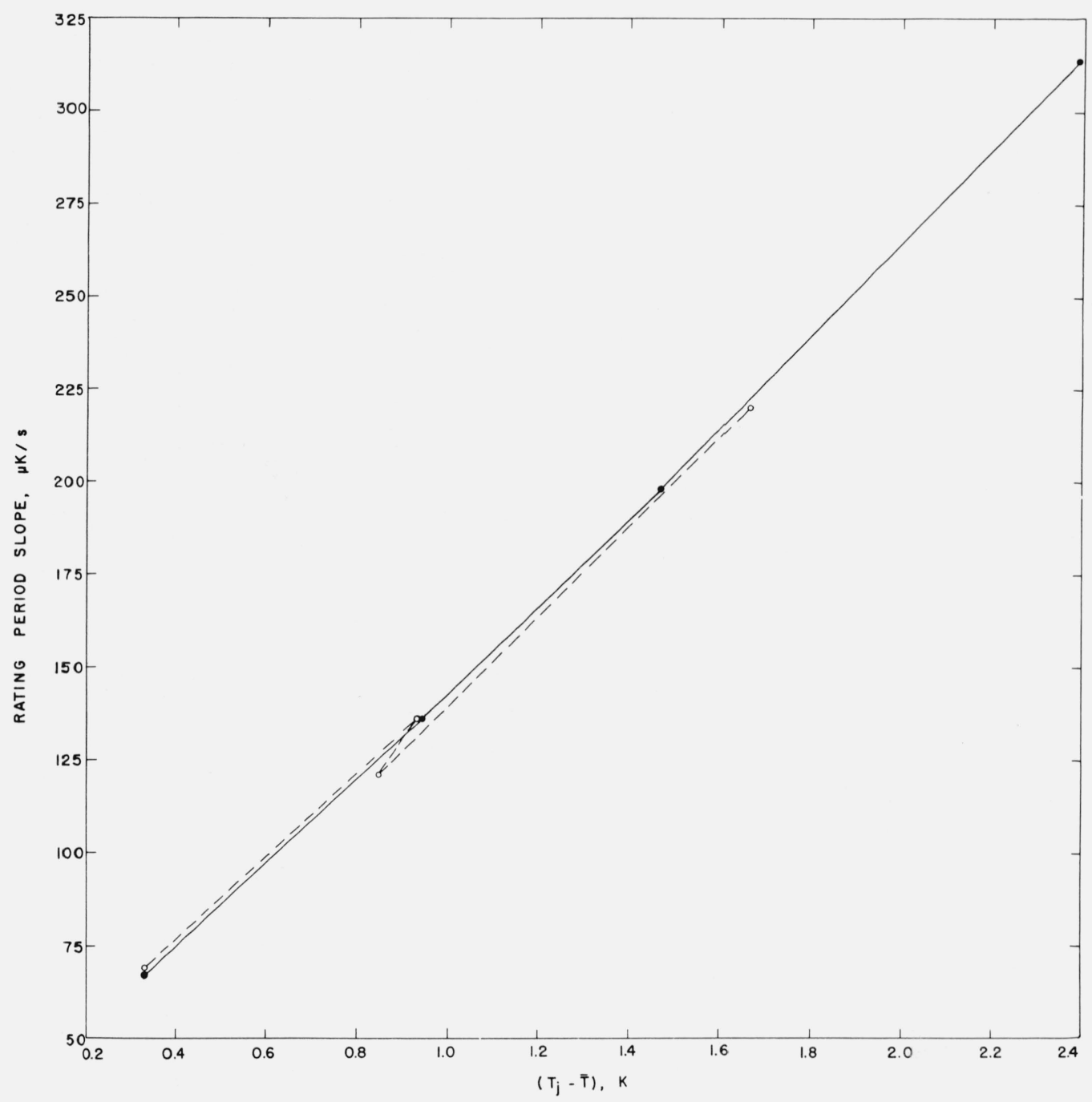

FIGURE 2. A plot of the rating period slopes as a function of the differences between the jacket temperature and the mean temperature of the rating period for 2 typical experiments using different procedures for measuring the enthalpy of solution of $\mathrm{KCl}$ (see table 3 for the data plotted).

The solid circles connected by continuous lines represent Expt. No. 17 (table 1, Method A); the open circles connected by broken lines represent Expt. No. 20 (table 2, Method B). The points on each line (from upper right to lower left) are for the rating period preceding the initial calibration, that preceding the reaction period, that following the reaction period, and that following the final calibration.

essentially the same for all of these experiments, and that the $k$ values for the initial calibrations are less scattered than those for the final calibrations. In the experiments where electrical energy was added during the reaction period (filled circles connected by solid lines), the $k$ values for the reaction period were a little more scattered than in the final calibration; this may have been the result of interrupting the stirring energy when the ampoule was broken. In the experiments where electrical energy was not added during the reaction period (open circles connected by broken lines), the $k$ values were widely scattered and all were larger than those for the calibrations; this scatter is too large to be attributable to the interruption of the stirring energy and may be the result of abnormal thermal lags or the effects of evaporation of water in the vessel.

It is evident that the $k$ values for the experiments in set 2 table 2 are the source of the erratic results. Therefore, these experiments and those for set 2 in table 1 were recalculated using $k$ values obtained from the final calibrations. The mean $\Delta H$ values thus obtained for the 2 sets agreed with each other but were about $0.1 \mathrm{~kJ} \cdot \mathrm{mol}^{-1}$ less than the value determined in the adiabatic calorimeter. The standard deviations were about 3 times those of set 2 (Method A) using the $k$ values obtained from the reaction.

In studying the data for the $k$ values, evidence was found of the existence of thermal gradients in the air space 
Table 3. Data plotted in figures 2 and 3 for experiments in tables 1 and 2 using the adequate stirring rate, 900 rpm.

\begin{tabular}{|c|c|c|c|c|c|c|c|c|c|c|c|}
\hline \multirow{2}{*}{$\frac{\text { Method }}{\text { Expt. No. }}$} & \multicolumn{5}{|c|}{ A } & \multicolumn{6}{|c|}{ B } \\
\hline & 9 & 12 & 13 & 14 & 17 & 20 & 23 & 24 & 26 & 27 & 30 \\
\hline $\begin{array}{l}\mathrm{Tj} / \mathrm{K} \\
(\mathrm{Tj}-\overline{\mathrm{T}}) / \mathrm{K} \text { for }\end{array}$ & 299.487 & 299.487 & 299.487 & 299.481 & 299.481 & 299.136 & 299.142 & 299.146 & 299.139 & 299.135 & 299.135 \\
\hline RPI & 2.388 & 2.388 & 2.341 & 2.393 & 2.387 & 1.672 & 1.626 & 1.685 & 1.686 & 1.661 & 1.609 \\
\hline RP2 & 1.575 & 1.404 & 1.418 & 1.380 & 1.471 & 0.844 & 0.879 & 0.831 & 0.894 & 0.893 & 0.825 \\
\hline RP 3 & 1.014 & 0.858 & 0.830 & 0.833 & 0.942 & 0.931 & 0.993 & 0.913 & 0.971 & 0.962 & 0.913 \\
\hline RP 4 & 0.422 & 0.267 & 0.230 & 0.291 & 0.331 & 0.329 & 0.367 & 0.300 & 0.343 & 0.335 & 0.304 \\
\hline \multicolumn{12}{|c|}{$\mathrm{Slope} / \mu \mathrm{K} \cdot \mathrm{s}^{-1}$ for } \\
\hline RP1 & 316 & 314 & 308 & 313 & 314 & 220 & 215 & 223 & 223 & 221 & 213 \\
\hline RP2 & 212 & 190 & 191 & 186 & 198 & 121 & 126 & 120 & 128 & 128 & 119 \\
\hline $\begin{array}{l}\text { RP } 3 \\
\text { RP4 }\end{array}$ & $\begin{array}{r}144 \\
77\end{array}$ & 126 & 124 & 122 & 136 & 136 & 140 & 131 & 138 & 139 & 132 \\
\hline RP4 & 77 & 60 & 59 & 61 & 67 & 69 & 69 & 62 & 68 & 67 & 62 \\
\hline$\left(\mathrm{T}_{\infty}-\mathrm{T}_{\mathrm{A}}\right) / \mathrm{K}$ & 2.030 & 1.974 & 1.941 & 1.960 & 2.000 & 1.404 & 1.410 & 1.403 & 1.430 & 1.419 & 1.358 \\
\hline $\begin{array}{l}\left(T_{\infty}-T_{r}\right) / K \\
\left(T_{\infty}-T_{B}\right) / K\end{array}$ & $\begin{array}{l}1.462 \\
0.960\end{array}$ & $\begin{array}{l}1.325 \\
0.822\end{array}$ & $\begin{array}{l}1.375 \\
0.834\end{array}$ & $\begin{array}{l}1.316 \\
0.818\end{array}$ & $\begin{array}{l}1.420 \\
0.895\end{array}$ & $\begin{array}{l}0.783 \\
0.914\end{array}$ & $\begin{array}{l}1.079 \\
0.909\end{array}$ & $\begin{array}{l}0.994 \\
0.849\end{array}$ & $\begin{array}{l}1.008 \\
0.915\end{array}$ & $\begin{array}{l}0.900 \\
0.878\end{array}$ & $\begin{array}{l}0.858 \\
0.839\end{array}$ \\
\hline $\mathrm{k}_{\mathrm{A}} \times 10^{-6} / \mathrm{s}^{-1}$ & 130 & 128 & 128 & 128 & 129 & 121 & 121 & 121 & 122 & 122 & 121 \\
\hline$k_{r} \times 20^{-6} / s^{-1}$ & 122 & 120 & 116 & 118 & 118 & 166 & 125 & 127 & 133 & 150 & 146 \\
\hline$k_{B} \times 10^{-6} / s^{-1}$ & 115 & 114 & 111 & 113 & 113 & 112 & 115 & 113 & 113 & 117 & 116 \\
\hline
\end{tabular}

between the vessel and the well. This would account for the temperature dependence of the $k$ values. These gradients present no serious problem as long as the temperatures during the experiments are reproduced, however, significant errors would occur in measurements at different temperatures as in $\Delta C_{p}$ measurements. Others using this type of calorimeter should be alert to this problem.

Possible evidence of an apparently ongoing endothermic process at the end of some of the reaction periods was obtained from values of the corrected temperature change calculated from 3 different reaction periods for the solution of $\mathrm{KCl}$ in each experiment. These values of $-\Delta T_{\text {corr }}$ as a function of the elapsed time after breaking the ampoule, $\left(t-t_{\mathrm{o}}\right)$, are plotted in figure 4. Electrical energy was added during the solution of $\mathrm{KCl}$ (Method A) for the 5 experiments plotted in the lower portion of the figure (shaded circles); the 3 values for each experiment were on an essentially straight horizontal line. Electrical energy was not added during the solution of $\mathrm{KCl}($ Method B) for the experiments plotted in the upper portion of figure 4. The "X"s represent values from the 5 experiments with the inadequate stirring rate, $400 \mathrm{rpm}$; and the open circles, the 6 experiments with the adequate stirring rate, $900 \mathrm{rpm}$. In each experiment, the " $\mathrm{X}$ " values are on an essentially straight horizontal line and some show a slight downward trend. However, the open circles for each experiment showed an increasing upward trend which varied significantly in magnitude between experiments; the most significant upward trends were in Expts. No. 20, 27, and 30 which also had the highest values for the enthalpy of solution.

If the reaction were complete and the constant power sources remained constant, the $3 \Delta T$ values should lie on a horizontal straight line as in the lower portion of figure 4 .
If the reaction were incomplete a diminishing upward trend should be observed in the $\Delta T$ values. However, the increasing upward trend most evident in Expts. No. 20, 27, and 30 could indicate on ongoing endothermic process such as the slow evaporation of water. It is understandable that the extent of such a process might vary in magnitude between experiments because of variations in glass and metal surface conditions, however, it is difficult to explain why they should be apparent at the higher stirring rate but not at the lower stirring rate.

The condensation and evaporation of water are a potential source of error by this Method B, but not by Method A where the calorimeter temperature increases throughout the experiment. However, this does not explain the high enthalpy values obtained by Method B at the high stirring rate. Errors due to thermal lags (which are doubled because the temperature changes in the calibrations are of opposite sign to that of the reaction period) are another possible cause of the high enthalpy values.

\subsection{Relative Jacket Temperature}

The most common practice in measurements with solutions in isoperibol calorimeters is to maintain the isothermal (or constant) temperature of the jacket slightly above the final temperature of the reaction vessel. However, in some laboratories [5,14], the jacket is maintained slightly below the final temperature of endothermic reactions (where electrical energy is not added). This was done to reduce the magnitude of the heat leak corrections, and the errors in such corrections. This procedure is objectionable because it may introduce errors due to condensation of $\mathrm{H}_{2} \mathrm{O}$ under some conditions. 


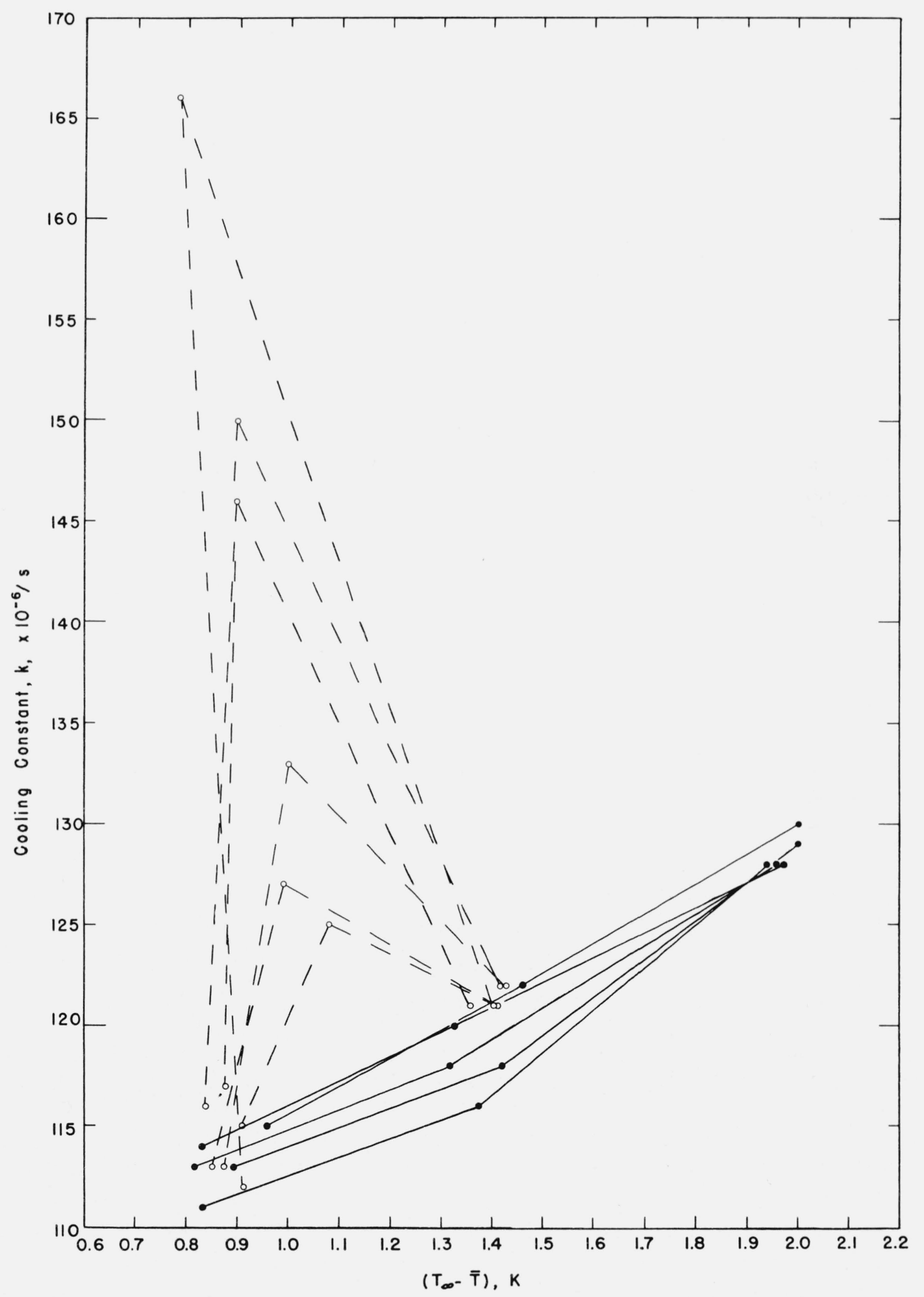

FigurE 3. A plot of the values for the cooling constants, $k$, for the electrical calibrations and for the reaction periods as a function of the differences between the convergence temperature and the mean temperature, $\left(T_{\infty}-T\right)$, for 5 experiments using Method A in table 1 (filled circles connected by continuous lines) and for 6 experiments using Method B in table 2 (open circles connected by broken lines) at the adequate stirring rate, $900 \mathrm{rpm}$; the data plotted are given in table 3. Each set of 3 points represents, from right to left, the values for the initial calibration, the reactionperiod, and the final calibration. 


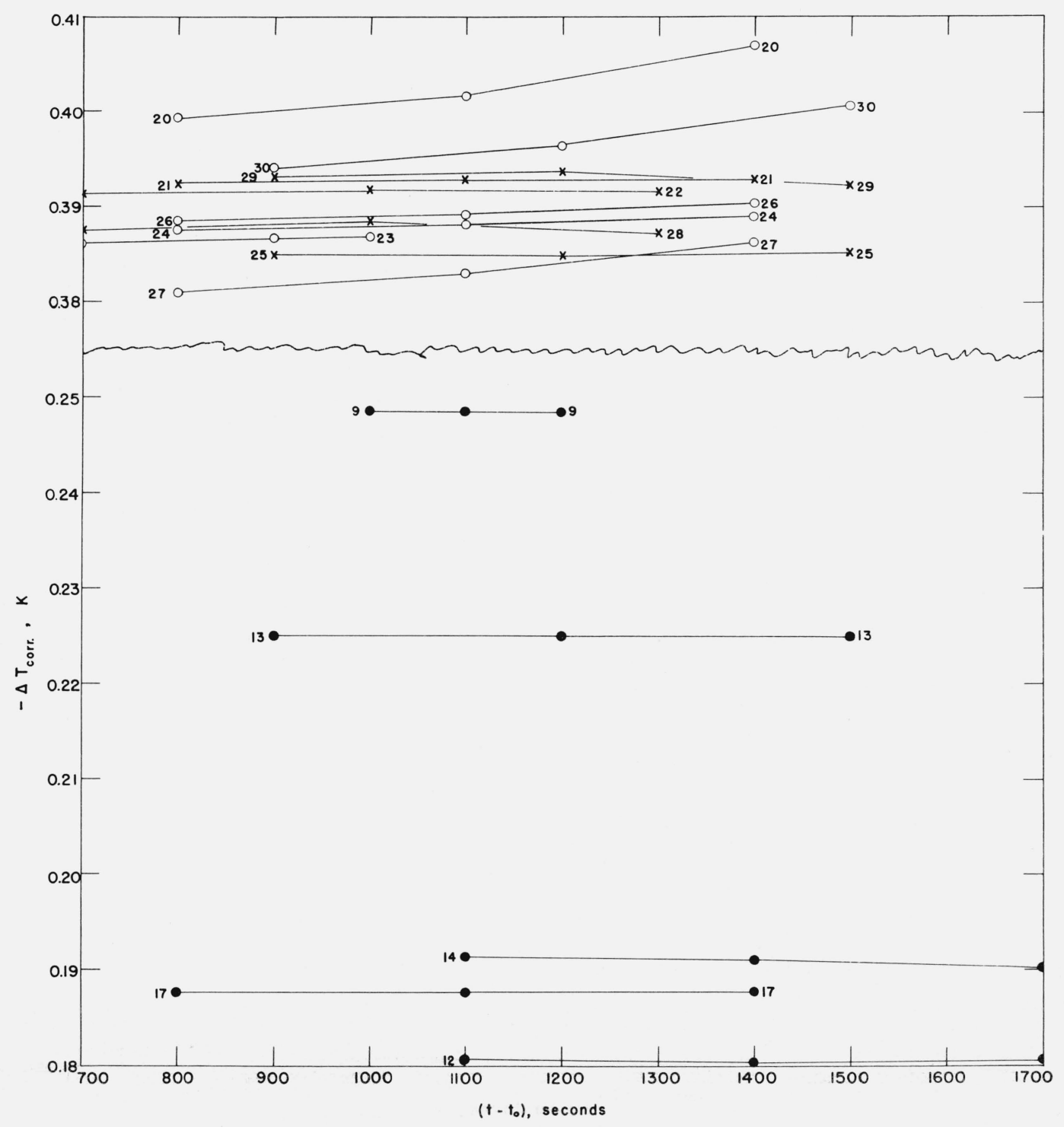

FIGURE 4. A plot of 3 corrected temperature changes calculated for each experiment as a function of the elapsed time after initiating the reaction. The number at the end of each group indicates the experiment number.

The shaded circle represents a value for an experiment in table 1 (Method A, $900 \mathrm{rpm}$ ); the "X," for an experiment in table 2 (Method B, $400 \mathrm{rpm}$ ); and the open circle, for an experiment in table 2 (Method B, $900 \mathrm{rpm}$ ). The upward trend in Expt. Nos. 20, 27, and 30 suggests an ongoing endothermic process.

In table 4 are the results of 4 experiments in which the jacket temperature was near the initial temperature of the first electrical calibration, the lowest temperature during an experiment. During the initial rating periods, the heating effect due to stirring was greater than the loss due to heat leak, and the result was positive differences between successive temperature readings; after the first calibration, however, the reverse was true and those differences were negative.

In Expts. 31 and 32 (table 4) electrical energy was added during the reactions (Method $\mathrm{A}^{\prime}$ ), and in Expts. 34 and 35, it was not added (Method B'); the observed temperature change for all of the calibrations was $0.4 \mathrm{~K}$. The highest stirring rate, $900 \mathrm{rpm}$, was used in these experiments. The corrections to the $\Delta T_{\text {obs }}$ are $1 / 5$ or $1 / 6$ of the comparable corrections in table 1 where the jacket temperature was above that of the vessel.

The values of $\Delta H^{\circ}(\infty, 298.15 \mathrm{~K})$ for Method $\mathrm{A}^{\prime}$ agree within the uncertainties with those of set 2 , Method $A$ and with the value from the adiabatic calorimeter. The values by Method B' show the large spread which was also observed in set 2 of Method B. In these measurements, 
able 4. Measurements of the enthalpy of solution of SRM 1655 (KC1) in $\mathrm{H}_{2} 0$ with the temperature of the calorimeter jacket below that of the reaction vessel at a stirring rate of $900 \mathrm{rpm}$.

(a) Calculation of enthalpy of solution:

\begin{tabular}{|c|c|c|c|c|c|c|c|c|c|c|c|c|c|c|c|}
\hline \multirow{3}{*}{$\begin{array}{r}\text { Expt. } \\
\text { No. }\end{array}$} & \multicolumn{2}{|c|}{ Mass } & \multicolumn{2}{|c|}{ Elect. Energy Equiv. } & \multirow{2}{*}{$\Delta \mathrm{T}_{\text {obs }}$} & \multirow[t]{2}{*}{ Correction } & \multirow[t]{2}{*}{ EE } & \multirow{2}{*}{$-q_{\text {vap }}$} & \multirow[t]{2}{*}{$-Q$} & \multirow{2}{*}{\multicolumn{2}{|c|}{$\Delta \mathrm{H}\left(\mathrm{T}_{\mathrm{r}}\right)$}} & \multirow[t]{2}{*}{$\mathrm{T}_{\mathrm{r}}$} & \multirow{2}{*}{$\operatorname{Corr}_{\mathrm{ST}}$} & \multirow[t]{2}{*}{$\Phi_{L}$} & \multirow[t]{2}{*}{$\Delta \mathrm{H}^{\circ}(\infty, 298.15 \mathrm{~K})$} \\
\hline & KC1 & $\mathrm{H}_{2} \mathrm{O}$ & Initial & Final & & & & & & & & & & & \\
\hline & & & & $\bar{K}$ & $\mathrm{~K}$ & $\mathrm{~K}$ & $\mathrm{~J}$ & $\mathrm{~J}$ & $\mathrm{~J}$ & $\mathrm{~J} / \mathrm{g}$ & $\mathrm{kJ} / \mathrm{mo} 1$ & $\bar{K}$ & $\mathrm{~kJ} / \mathrm{mol}$ & $\mathrm{kJ} / \mathrm{mol}$ & $\mathrm{kJ} / \mathrm{mol}$ \\
\hline \multicolumn{16}{|c|}{ EE added (Method $\left.A^{\prime}\right)$ : } \\
\hline 31 & 0.79456 & 107.365 & 482.49 & 481.23 & 0.14572 & -0.04152 & 277.484 & 0.012 & 187.248 & 235.663 & 17.569 & 298.1875 & 0.006 & 0.336 & $17.239^{\mathrm{a}}$ \\
\hline 32 & .79312 & 107.326 & 482.42 & 479.99 & .14803 & -.02913 & 271.937 & .012 & 186.675 & 235.368 & 17.547 & 298.1594 & .001 & .336 & $17.212 \mathrm{a}$ \\
\hline \multicolumn{16}{|c|}{ EE not added (Method $\left.B^{\prime}\right)$ : } \\
\hline 34 & 0.79688 & 107.360 & 482.66 & 480.67 & -0.35871 & 0.03284 & -- & 0.012 & 188.584 & 236.653 & 17.643 & 298.1874 & 0.006 & 0.336 & 17.313 \\
\hline 35 & .80335 & 107.327 & 483.04 & 480.56 & -.35232 & .04011 & -- & .012 & 189.061 & 235.340 & 17.545 & 298.1810 & .005 & .336 & 17.214 \\
\hline
\end{tabular}

(b) Other Calorimetric parameters:

\begin{tabular}{|c|c|c|c|c|c|c|c|c|c|}
\hline $\begin{array}{l}\text { Expt. } \\
\text { No. }\end{array}$ & $\mathrm{T}_{\mathrm{A}}$ & $\mathrm{T}_{\mathrm{B}}$ & $T_{\varepsilon}-T_{r}$ & $\mathrm{~T}_{j}$ & $\mathrm{~T}_{\mathrm{Ai}}$ & $\begin{array}{l}\text { Reaction } \\
\text { Period }\end{array}$ & $k \times 10^{-6}$ & $\mathrm{U} \times 10^{-6}$ & $\mathrm{~T}(\infty)$ \\
\hline & $-{ }^{\mathrm{A}}$ & $\mathrm{K}$ & $\bar{K}^{r}$ & $\mathrm{~K}$ & K & s & $\mathrm{s}^{-1}$ & $\mathrm{~K} / \mathrm{s}$ & $\mathrm{K}$ \\
\hline \multicolumn{10}{|c|}{ EE added (Method $\left.\mathrm{A}^{\prime}\right)$ : } \\
\hline 31 & 297.898 & 298.425 & -0.026 & 297.713 & 297.675 & 1800 & 94 & 28.9 & 298.020 \\
\hline 32 & 297.878 & 298.395 & -.023 & 297.714 & 297.667 & 1400 & 96 & 29.0 & 298.017 \\
\hline \multicolumn{10}{|c|}{ EE not added (Method $\left.\mathrm{B}^{\prime}\right)$ : } \\
\hline 34 & 298.170 & 298.234 & 0.015 & 297.916 & 297.962 & 1300 & 114 & 37.5 & 298.244 \\
\hline 35 & 298.161 & 298.226 & .012 & 297.915 & 297.956 & 1500 & 110 & 35.5 & 298.237 \\
\hline
\end{tabular}

a Requires correction of $0.01 \mathrm{~kJ} \cdot \mathrm{mol}^{-1}$ for failure to measure energy equivalents over the same temperature range as that for the reaction.

there appears to be no significant advantage nor disadvantage to having the jacket temperature below that of the reaction vessel. Therefore, the safer procedure of Method A which eliminates the possibility of $\mathrm{H}_{2} \mathrm{O}$ condensation errors, seems more desirable than Method A'; apparently the larger heat leak corrections are of sufficient accuracy to eliminate the need for reducing them.

\section{Exothermic Reactions of TRIS (SRM 724a) in 0.1 M HCl}

The results of seven measurements of the enthalpy of reaction of SRM 724a in $0.1 \mathrm{M} \mathrm{HCl}$ are given in table 5; the jacket temperature was above that of the vessel in these experiments. These measurements were made with the following objectives: (1) to check the value previously obtained by Brunetti [8] for this reaction using essentially the same calorimetric system, (2) to determine the magnitude of errors in measurements of exothermic reactions with isoperibol calorimeters if the reaction measurements are not made over the same temperature range as the electrical calibrations, and (3) to determine the cause of some erratic results obtained with this reaction in the adiabatic calorimeter.

Unfortunately the results are not conclusive in regard to the third objective. They are reported here primarily as a caution to others who may use this reaction for occasional checks on the operation of calorimeters. It is known that this reaction is relatively insensitive to the concentration of the $\mathrm{HCl}$ solutions and a few percent variation in concentration causes no significant change in the value for the enthalpy of reaction. Thus, when the preparation and analysis of standard stock solutions is not a routine operation in a laboratory, there is a temptation to use a portion of an old solution instead of preparing a new one. In this laboratory, standardized $\mathrm{HCl}$ stock solutions are usually stored in 2-L polyethylene bottles. When these solutions were freshly prepared (within a few months) the enthalpy measurements were reproducible within expected limits. However, in later work the TRIS checks of the calorimeter were made only at intervals of one or two years when the adiabatic calorimeter was dismantled to replace o-ring vacuum seals.

The following disturbingly erratic results were obtained over the past few years:

\begin{tabular}{lll}
\hline Date of Experiment & $\begin{array}{l}\text { HCl Soln. No. } \\
\text { (date prepared) }\end{array}$ & $-\Delta \mathrm{H}(298.15 \mathrm{~K})$, \\
\hline
\end{tabular}

\begin{tabular}{lcc}
\hline & & $\mathrm{kJ} \cdot \mathrm{mol}^{-1}$ \\
November 1975 & 64 (Nov. 1975) & 29.824 \\
& & 29.774 \\
October 1977 & 64 (Nov. 1975) & 29.771 \\
June 1978 & & 29.754 \\
& 66 (Nov. 1975) & 29.820 \\
& & 29.906 \\
& & 33.106 \\
\end{tabular}

Most of these values are in poor agreement with the work [7] reported in $1973\left[-(29.770 \pm 0.002) \mathrm{kJ} \cdot \mathrm{mol}^{-1}\right.$, the experimental imprecision is given]. Originally it was assumed that the first value for $\Delta H$ shown here was the result of a weighing error since it was the first of a series of 
Table 5. Measurements of enthalpy of solution of SRM $724 \mathrm{a}$ (TRIS) in $0.1 \mathrm{~mol} \cdot \mathrm{dm}^{-3} \mathrm{HCl}$ comparing solutions with different histories and two different calorimetric procedures.

(a) Calculation of enthalpy of solution:

\begin{tabular}{|c|c|c|c|c|c|c|c|c|c|c|c|c|c|c|}
\hline \multirow{2}{*}{$\begin{array}{r}\text { Expt. } \\
\text { No. }\end{array}$} & \multirow{2}{*}{$\begin{array}{l}\text { Soln. } \\
\text { Code }\end{array}$} & \multicolumn{2}{|c|}{ Mass } & \multicolumn{2}{|c|}{ Elect. Energy Equiv. } & \multirow{2}{*}{\begin{tabular}{c|}
$\Delta \mathrm{T}_{\text {obs }}$ \\
$\mathrm{K}$
\end{tabular}} & \multirow{2}{*}{\begin{tabular}{|c|} 
Correction \\
$\mathrm{K}$ \\
\end{tabular}} & \multirow{2}{*}{\begin{tabular}{|c|}
$-\mathrm{q}_{\text {vap }}$ \\
$\mathrm{J}$
\end{tabular}} & \multirow{2}{*}{$\overline{\mathrm{Q}}$} & \multicolumn{2}{|c|}{$-\Delta \mathrm{H}\left(\mathrm{T}_{\mathrm{r}}\right)$} & \multirow{2}{*}{$\frac{{ }^{T} r}{K}$} & \multirow{2}{*}{\begin{tabular}{|c} 
Corr $_{\text {ST }}$ \\
$\mathrm{kJ} / \mathrm{mol}$
\end{tabular}} & \multirow{2}{*}{$\frac{-\Delta \mathrm{H}(298.15 \mathrm{~K})}{\mathrm{kJ} / \mathrm{mol}}$} \\
\hline & & SRM 724a & HC1 Soln. & Initial $\mathrm{J}$ & Final & & & & & $\mathrm{J} / \mathrm{g}$ & $\mathrm{kJ} / \mathrm{mol}$ & & & \\
\hline \multicolumn{15}{|c|}{ Calorimeter not cooled after first calibration or after reaction (Method $\mathrm{C}$ ): } \\
\hline 36 & APB-poly & 0.49283 & 109.396 & 490.01 & 489.55 & 0.50218 & 0.25096 & 0.012 & 123.045 & 249.690 & 30.246 & 298.3856 & 0.041 & 30.29 \\
\hline 37 & 72-glass & .47782 & 109.360 & 490.43 & 492.46 & .40414 & .16543 & .012 & 117.325 & 245.542 & 29.744 & 298.0580 & -.013 & 29.73 \\
\hline 38 & 66-poly & .49253 & 109.378 & 489.26 & 489.94 & .47686 & .22990 & .012 & 120.924 & 245.515 & 29.741 & 298.1734 & .004 & 29.74 \\
\hline b 39 & 72-glass & .50010 & 109.352 & 489.24 & 489.62 & .48187 & .23073 & .012 & 122.927 & 245.806 & 29.776 & 298.0841 & -.011 & 29.76 \\
\hline 40 & 66-po1y & .49690 & 109.341 & 489.85 & 490.67 & .45486 & .20668 & .012 & 121.685 & 244.888 & 29.665 & 298.2254 & .013 & 29.68 \\
\hline
\end{tabular}

Calorimeter cooled after first calibration and after reaction (Method $D$ ):

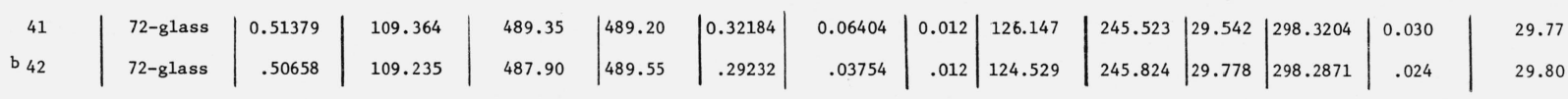

(b) Other Calorimetric parameters:

\begin{tabular}{r|c|c|c|c|c|c|c|c|c}
\hline $\begin{array}{r}\text { Expt. } \\
\text { No. }\end{array}$ & $\mathrm{T}_{\mathrm{A}}$ & $\mathrm{T}_{\mathrm{B}}$ & $\mathrm{T}_{\varepsilon}-\mathrm{T}_{\mathrm{r}}$ & $\mathrm{T}_{\mathrm{j}}$ & $\mathrm{T}_{\mathrm{Bf}}$ & $\begin{array}{c}\text { Reaction } \\
\text { Period }\end{array}$ & $\mathrm{k} \times 10^{-6}$ & $\mathrm{U} \times 10^{-6}$ & $\mathrm{~T}(\infty)$ \\
\hline & $\mathrm{K}$ & $\mathrm{K}$ & $\mathrm{K}$ & $\mathrm{K}$ & $\mathrm{K}$ & $\mathrm{s}$ & $\mathrm{s}^{-1}$ & $\mathrm{~K} / \mathrm{s}$ & $\mathrm{K}$
\end{tabular}

\begin{tabular}{|c|c|c|c|c|c|c|c|c|c|}
\hline \multicolumn{10}{|c|}{ Calorimeter not cooled after first calibration or after reaction (Method $\mathrm{C}$ ): } \\
\hline 36 & 297.633 & 298.973 & -0.083 & 298.808 & 299.196 & 1400 & 122 & 22.4 & 299.632 \\
\hline 37 & 297.363 & 298.590 & -.082 & 299.383 & 298.800 & 1000 & 125 & 15.2 & 299.504 \\
\hline 38 & 297.489 & 298.702 & -.078 & 299.384 & 298.909 & 1500 & 120 & 23.9 & 299.583 \\
\hline b 39 & 297.426 & 298.632 & -.055 & 299.383 & 298.857 & 1700 & 123 & -9.9 & 299.302 \\
\hline 40 & 297.503 & 298.813 & -.067 & 299.385 & $\begin{array}{c}299.080 \\
T_{\text {Af }}\end{array}$ & 1400 & 128 & 27.5 & 299.620 \\
\hline \multicolumn{10}{|c|}{ Calorimeter cooled after first calibration and after reaction (Method D): } \\
\hline 41 & 298.349 & 298.354 & 0.031 & 298.618 & 298.557 & 1300 & 107 & 31.1 & 298.908 \\
\hline b 42 & 298.327 & 298.271 & .012 & 298.617 & 298.144 & 1400 & 108 & 1.3 & 298.629 \\
\hline
\end{tabular}

\footnotetext{
a Soln. Code: "poly" indicates that the solution was stored in a polyethylene bottle.

"glass" indicates that the solution was prepared and stored in a borosilicate glass container.

"APB" was $0.1011 \mathrm{~mol} \cdot \mathrm{dm}^{-3} \mathrm{HCl}$ solution prepared about 1972 and used by Brunetti in previous work [8].

" 66 " was a $0.0994 \mathrm{~mol} \cdot \mathrm{dm}^{-3} \mathrm{HCl}$ solution prepared in November 1975 and used in expts. with the

adiabatic calorimeter reported in this work.

" 72 " was a $0.100 \mathrm{~mol} \cdot \mathrm{dm}^{-3} \mathrm{HCl}$ solution freshly-prepared by dilution of a $1.00 \mathrm{~mol} \cdot \mathrm{dm}^{-3} \mathrm{HCl}$ solution

(stored in a glass flask) prepared by Brunett1 in 1971 using constant boiling HCl.
}

b Stirring rate $=300 \mathrm{rpm} ; 900 \mathrm{rpm}$ in all other experiments.

three and the last two were in good agreement with previous work. However, the later measurements raised questions. Other reactions measured during this period, such as $\mathrm{KCl}$ in $\mathrm{H}_{2} \mathrm{O}$ [6], agreed well with other published values. Low values for the TRIS reaction might be explained by leakage of the sample container, but the high values were not expected in view of the fact that the calorimeter was definitely vented to the atmosphere. There appeared to be a trend toward increasing values as the $\mathrm{HCl}$ solutions (stored in polyethylene bottles) aged.

For the work in the isoperibol calorimeter three $\mathrm{HCl}$ solutions (described in table 5) were used. Three experiments $(36,38$, and 40$)$, where the solutions had been stored 4 years or more in polyethylene bottles, again produced erratic results; the first value was much larger than the published value and the other two were somewhat smaller. Cursory comparison with Expt. 37 and 39 using the freshly prepared $\mathrm{HCl}$ solution stored in glass suggests similar results; however, further consideration of the 4 experiments using Soln. 72 reveals a logical pattern which will be discussed following some background information.

Brunetti's measurements of this reaction were made at $300 \mathrm{rpm}$ stirring rate; our visual observation indicated that this was inadequate. Even at $550 \mathrm{rpm}$ the sample was not completely stirred up in the solution. Therefore, all of the experiments in table 5 used $900 \mathrm{rpm}$, the highest stirring rate, except Expts. 39 and 42 at 300 rpm for comparison.

In addition, Brunetti cooled the calorimeter after the measurements for the first calibration and after those for the reaction, so that the measurements for the two calibrations and the reaction were performed over the same temperature range. This desirable but time-consuming procedure is not always followed, in fact, it is impossible in some calorimeters without a change in design.

In Expts. 41 and 42 the calorimeter was cooled after the first calibration and after the reaction (Method D) by passing air at the rate of $10 \mathrm{~L} \cdot \mathrm{min}^{-1}$ through a tube (about $1 \mathrm{~cm}$ in diameter) in the top of the well. This air was dried 
in a tower containing a desiccant, cooled in an ice-bath heat exchanger, and passed through well-insulated tubing into the well. The necessary cooling, accomplished in about 15 min, was followed by an equilibration period of about 15 min, and two additional rating periods were required because of the temperature discontinuity; this resulted in an increase of about 50 percent in the time required for an experiment.

In table 5 there are 4 experiments where the freshly prepared Soln. 72 was used. Expt. 41 employed the most desirable procedure (Method D) at the highest stirring rate, and the value for $\Delta H(298.15 \mathrm{~K})$ agrees with that obtained with the adiabatic calorimeter [7]; Expt. 42 at 300 rpm used by Brunetti agrees with his value $-(29.79 \pm 0.03)$ $\mathrm{kJ} \cdot \mathrm{mol}^{-1}$ [8]. (This difference in the two stirring rates is in the opposite direction of that observed in the endothermic $\mathrm{KCl}$ reaction and is to be expected since a "hot spot" is formed instead of a "cold spot.") Using the quicker but less desirable Method C, where the calorimeter temperature increased continuously and was not interrupted by cooling, $29.73 \mathrm{~kJ} \cdot \mathrm{mol}^{-1}$ was obtained at the highest stirring rate, and $29.76 \mathrm{~kJ} \cdot \mathrm{mol}^{-1}$ at $300 \mathrm{rpm}$; the difference is precisely the same as that from Method D. This indicates good reproducibility in the measurements with the freshly prepared Soln. 72. The error resulting from failure to measure the energy equivalents of the systems over the same temperature range as the reaction was 0.13 percent of the enthalpy of reaction. In these experiments $\Delta T_{\text {obs }}$ was approximately equal in the calibration and in the reaction periods; in comparable $\mathrm{KCl}$ experiments, $\Delta T_{\text {obs }}$ of the reaction was only half that of the calibrations and the error would also be expected to be about half or 0.06 percent.

The reason for the erratic results obtained in both calorimeters apparently from using solutions stored in polyethylene bottles rather than glass, is unknown. Perhaps it is in some way related to the high values previously reported [7] for this reaction in the presence of $\mathrm{O}_{2}$ and high concentrations of $\mathrm{CO}_{2}$ dissolved in the solution; perhaps the polyethylene plasticizer is involved; or perhaps exposure of the solution to the atmosphere under some conditions releases dissolved gases and retains them under other conditions. These are problems which cannot be answered here.

\section{Conclusions and Recommended Procedures}

In table 6 are summarized the values for the enthalpies of solution of $\mathrm{KCl}$ and TRIS measured in this work using high and low stirring speeds and various commonly used calorimetric procedures. These values are compared with those obtained in an adiabatic calorimeter [6,7] in which the heat transfer between the reaction vessel and the environment is negligible. The $\mathrm{Sdm}$ of the $\mathrm{KCl}$ measurements in the isoperibol calorimeter was usually $0.02 \mathrm{~kJ} \cdot \mathrm{mol}^{-1}$ or less except under conditions which

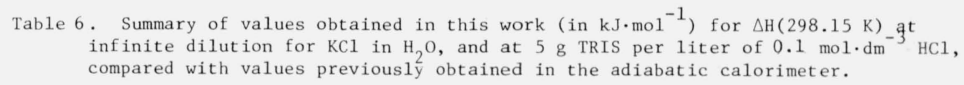


produced erratic results. Insufficient data were obtained for the TRIS reactions to calculate meaningful Sdm values, but it is reasonable to assume that the order of magnitude is $0.01 \mathrm{~kJ} \cdot \mathrm{mol}^{-1}$.

The results in table 6 indicate errors in heat leak corrections in this isoperibol calorimeter due to (1) inadequate stirring in the endothermic reaction $(-0.5 \%)$ and in the exothermic reaction $(+0.1 \%),(2)$ failure to have $\Delta T$ of the same sign in the calibrations and in the reaction period $(+0.3 \%$ or more because of erratic results), and (3) failure to measure the energy equivalents and the reaction over the same temperature range $(-0.1 \%)$. Erratic results were also obtained for the exothermic TRIS reaction in both the isoperibol and the adiabatic calorimeters when $\mathrm{HCl}$ solutions which had been stored for long periods in polyethylene bottles were used. The magnitude of the errors shown here may be different in calorimeters of other designs.

It would be difficult in some calorimeters to determine the magnitude of some of the errors found in this work. Some solution calorimeters lack the capability for making direct measurements of electrical energy introduced into the calorimeter, and in some the system cannot be cooled to a desired temperature without disturbing the composition of the system. In lieu of measuring these systematic errors for each calorimeter, such errors will be minimized or eliminated and the accuracy of the measurements will be improved if the following recommended procedures are used.

\section{Recommended Procedures for Calorimeters Requiring Heat Leak Corrections:}

1. Visual observation of adequate stirring for each reaction is essential.

In order to observe the sample when the reaction is initiated, the reaction vessel should be mounted outside the jacket or bath, and assembled (using the same stirring mechanism) as in calorimetric experiments. If the reaction vessel is not transparent, a glass replica or "dummy" vessel should be constructed for this purpose. In some cases it may be possible to achieve adequate stirring by eliminating large (or small) particles through sieving. Otherwise it would be necessary to increase the stirring speed or redesign the stirring mechanism to prevent the sample from dropping to the bottom of the vessel or floating on the surface of the solution.

2. Observed $\Delta T$ must be of the same sign and approach the same magnitude for the reaction and for the calibrations.

This is not difficult to achieve for exothermic reactions where the calorimeters are calibrated electrically. For endothermic reactions where the calibrations are done by the addition of electrical energy, the reaction should also be accompanied by the addition of precisely measured electrical energy in order to maintain a positive $\Delta T$. Ideally the EE added during the reaction should equal that added during the calibrations plus the energy absorbed by the reaction. (In this work, no significant error was found when the observed $\Delta T$ of the reaction period was about half that for the calibrations.) If the instrumentation for the precise measurement of the electrical energy is not available, a less desirable alternative is to calibrate using endothermic standard reference reactions [14] which would give negative $\Delta T_{\text {obs }}$ for the reaction and the calibrations. This is less desirable because (1) the decreasing temperatures may cause errors due to condensation of water, (2) there may be a loss in significance in values for the cooling constant, and (3) the uncertainty in the enthalpy value for the reference reaction must be added to the experimental uncertainty. The uncertainty in precise electrical energy measurements is usually less than that assigned to reference reactions.

\section{Measurements for the reaction period must be in the same} temperature range as those for the calibrations.

The calorimeter should be cooled after measurements for the initial calibration and after those for the reaction if $\Delta T$ is positive, or heated, if $\Delta T$ is negative. The latter usually presents no problem, however the design of some calorimeters, i.e., the Dewar types, make it difficult if not impossible to cool the reaction vessel without changing the composition of the contents, and the large thermal lags would require long periods of equilibration. An alternative would be to determine the magnitude of the errors involved with the normal procedure by calibrating with an endothermic reference reaction then heating electrically as a "reaction" period; in another experiment, reverse the procedure with an electrical calibration followed by an endothermic reference reaction. In this way the errors due to thermal lags should be cancelled and the mean of the two experiments could be compared with the result obtained in the normal procedure where the temperature ranges of the calibrations and the reaction are different.

\section{Maintain the jacket temperature above that of the reaction vessel.}

Our measurements showed no significant difference between the results where the jacket temperature was above and below that of the reaction vessel. There appears to be no advantage nor disadvantage in either case; however, when the jacket temperature is below that of the vessel errors due to condensation of $\mathrm{H}_{2} \mathrm{O}$ might be introduced under some conditions. 
In our earlier study on $\mathrm{KBr}$ [5] the isoperibol results of Efimov showed a puzzling curvature in the plot of the values for the enthalpy of solution of $\mathrm{KBr}$ versus concentration of the final solutions. It now appears that this was due to a combination of errors from thermal lags and inadequate stirring. At the lower concentrations both errors were small. As the concentration increased, the errors due to thermal lags increased giving larger enthalpy values. At the highest concentrations the errors due to inadequate stirring dominated and the enthalpy values decreased. Neither of these problems was present in the adiabatic calorimeter.

The errors revealed in this work are all derived from departures from ideality in the calculation of heat leak corrections. The imprecision of these measurements was 0.1 percent or less, but errors of as much as 0.5 percent were detected; these errors could be much greater in other calorimeters under some conditions. Thus, realistic uncertainties in values for enthalpies of solution may amount to several percent due to errors in heat leak corrections unless they are shown to be absent.

The author expresses her gratitude and appreciation to R. L. Nuttall for his assistance and advice in the restoration of this calorimetric system and the computer programs used in this work, and for his interpretation of the experimental results.

\section{References}

[1] Churney, K. L., West, E. D., and Armstrong, G. T., A Cell Model for Isoperibol Calorimeters, NBSIR 73-184 (Apr. 1973).
[2] Churney, K. L., Armstrong, G. T., and West, E. D., Microcalorimetry-How Accurate?, in Status of Thermal Analysis, O. Menis, Editor, NBS Special Publication 338 (Oct. 1970).

[3] West, E. D., and Churney, K. L., A Two-Body Model for Calorimeters with Constant Temperature Environment, J. Appl. Phys. 39, No. 9, 4206-4215 (Aug. 1968).

[4] West, E. D., and Churney, K. L., Theory of Isoperibol Calorimetry for Laser Power and Energy Measurements, J. Appl. Phys. 41, No. 6, 2705-2712 (May 1970).

[5] Efimov, M. E., Kleviachuk, G. N., Medvedev, V. A., and Kilday, M. V., Enthalpies of Solution of $\mathrm{KBr}, \mathrm{KI}, \mathrm{KIO}_{3}$, and $\mathrm{KIO}_{4}$, J. Res. Nat. Bur. Stand. (U.S.) 84, No. 4, 273-286 (July-Aug. 1979).

[6] Kilday, M. V., Enthalpy of Solution of SRM $1655(\mathrm{KCl})$ in $\mathrm{H}_{2} \mathrm{O}$, J. Res. Nat. Bur. Stand. (U.S.) 85, No. 6, 467-481 (Nov.-Dec. 1980).

[7] Prosen, E. J., and Kilday, M. V., Enthalpies of Reaction of Tris(hydroxymethyl)aminomethane in $\mathrm{HCl}(\mathrm{aq})$ and in $\mathrm{NaOH}(\mathrm{aq}), \mathrm{J}$. Res. Nat. Bur. Stand. (U.S.) 77A (Phys. and Chem.) No. 4, 581. 597 (Sept.-Oct. 1973).

[8] Brunetti, A. P., Prosen, E. J., and Goldberg, R. N., The Enthalpy of Reaction of Tris(hydroxymethyl)aminomethane with Hydrochloric Acid, J. Res. Nat. Bur. Stand. (U.S.) 77A (Phys. and Chem.) No. 5, 599-606 (Sept.-Oct. 1973).

[9] Prosen, E. J., and Kilday, M. V., An Adiabatic Solution Calorimeter and Measurements of a Standard Reaction for Solution Calorimetry, J. Res. Nat. Bur. Stand. (U.S.) 77A (Phys. and Chem.) No. 2, 179-203 (Mar.-Apr. 1973).

[10] Kilday, M. V., and Prosen, E. J., The Enthalpy of Solution of Low Quartz ( $\alpha$-quartz) in Aqueous Hydrofluoric Acid, J. Res. Nat. Bur. Stand. (U.S.) 77A (Phys. and Chem.) No. 2, 205-215 (Mar.-Apr. 1973).

[11] Commission on Atomic Weights, Pure and Appl. Chem. 47, 75-95 (1976).

[12] Cox, J. D., Collator, and Herington, E. F. G., Editor, Recommended Reference Materials for Realization of Physicochemical Properties, Pure and Appl. Chem. 40, 399-450 (1974).

[13] Parker, V. B., Thermal Properties of Uni-univalent Electrolytes Nat. Stand. Ref. Data Ser., Nat. Bur. Stand. (U.S.) 2, 66 pages (Apr. 1965).

[14] Montgomery, R. L., Melaugh, R. A., Lau, C.-C., Meier, G. H., Chan, H. H., and Rossini, F. D., Determination of the Energy Equivalent of a Water Calorimeter with a Standard Substance, J. Chem. Thermodynamics 9, 915-936 (1977). 
